\title{
Sulfur Dioxide and Glutathione Alter the Outcome of Microoxygenation
}

\author{
Angelita Gambuti, ${ }^{1,2}$ Guomin Han, ${ }^{1,3}$ Ana L. Peterson, ${ }^{1}$ \\ and Andrew L. Waterhouse ${ }^{1 *}$
}

\begin{abstract}
Cabernet Sauvignon wines with low and high levels of $\mathrm{SO}_{2}$ and glutathione (GSH) were treated with microoxygenation (MOx) in a $23 \mathrm{~L}$ pilot experiment. Treatment generally increased $\mathrm{O}_{2}$, aldehydes, and derived products while decreasing anthocyanins, vanillin reactive flavonoids, and $\mathrm{SO}_{2}$. During the treatment, when free $\mathrm{SO}_{2}$ was depleted in the low GSH wine, dissolved oxygen levels collapsed, with a concomitant increase of acetaldehyde, pyranoanthocyanins, polymeric pigments, and acetaldehyde acetals. This outcome indicates a possible acceleration of the Fenton oxidation of ethanol and other oxidation reactions by way of direct free radical reactions with oxygen. In wines containing high levels of GSH, anthocyanins were protected, revealing a protective effect for GSH for the first time. However, the protection was only partial, and while GSH may be effective in preventing the loss of volatile thiols, its use does not prevent color stabilization in red wines. Because both $\mathrm{SO}_{2}$ and $\mathrm{GSH}$ are able to modulate the reactions initiated by MOx, but have somewhat dissimilar reactions, it may be possible to manage oxidation outcomes by choosing one or the other during wine processing and aging. Because $\mathrm{SO}_{2}$ and $\mathrm{O}_{2}$ levels are related to large differences in MOx reaction rates, those levels are candidate indicators of the rate of MOx oxidation. Alternatively, the levels of acetaldehyde acetals may be useful indicators of the cumulative extent of oxidation under MOx conditions.
\end{abstract}

Key words: microoxygenation, dissolved oxygen, glutathione, sulfur dioxide, red wine

Mild oxygenation processes can impart benefits to a broad range of red wines by contributing to softening of tannin harshness, stabilizing color, and decreasing vegetative aromas (Atanasova et al. 2002, Cano-López et al. 2008, Cejudo-Bastante et al. 2011a, 2011b). Because microoxygenation (MOx) can promote these effects in a short time, allowing a rapid improvement of red wine quality, this practice has become widely used in winemaking (Gómez-Plaza and Cano-López 2011, Schmidtke et al. 2011). Nevertheless, there are several serious issues associated with the application of MOx. Excessive oxygen can result in the appearance of oxidation-spoiled aromas, loss of color, precipitation of colorant matter, and development of off-flavors (Cano-López et al. 2008, McCord 2003). Although many studies have been performed on evaluating the effect of MOx on wine composition and sensory characteristics (Arapitsas et al. 2012, Cejudo-Bastante et al.

${ }^{1}$ Department of Viticulture and Enology, University of California, Davis, CA 95616; ${ }^{2}$ Department of Agricultural Sciences, University of Naples "Federico II," viale Italia 83100, Avellino, Italy; and ${ }^{3}$ College of Enology, Northwest A \& F University, Yangling, Shaanxi 712100, PR China.

*Corresponding author (alwaterhouse@ucdavis.edu; fax: 530-752-0382)

Acknowledgments: The authors thank POR CAMPANIA FSE 2007/2013. Sviluppo di Reti di Eccellenza tra Università - Centri di Ricerca - Imprese. PROGETTO CARINA "Sicurezza, sostenibilità e competitività nelle produzioni agroalimentari della Campania" CUP B25B09000080007 for the award of a grant. The authors also thank Michael R. Webb for helpful assistance with the microoxygenation system preparation.

Manuscript submitted Dec 2014, revised May 2015, accepted Jun 2015

Copyright $(\subseteq 2015$ by the American Society for Enology and Viticulture. All rights reserved.

doi: 10.5344/ajev.2015.15005 2011a, 2011b, Gambuti et al. 2013), measuring the progress of MOx continues to be difficult due to the lack of key chemical indicators of the process.

The general chemistry of wine oxidation is widely accepted. First, molecular oxygen (triplet state) cannot directly react with wine organic compounds (singlet state); however, it can accept electrons by interacting with transition metals, iron and copper ions, in the presence of catechol (Danilewicz 2011). The catechol is oxidized to a quinone, and oxygen is reduced to hydrogen peroxide. In a subsequent step, ferrous or cuprous species react with hydrogen peroxide in the Fenton reaction to yield the most reactive oxidant, the hydroxyl radical. This reacts with all organic constituents in proportion to concentrations (Elias et al. 2009) and with a 10 -fold excess of ethanol relative to other compounds; acetaldehyde is the major product of oxidation.

Reactions involving acetaldehyde are among the most significant for the evolution of wine phenolics during aging. Acetaldehyde reacts with anthocyanins and flavanols to form ethyl-linked oligomers (Es-Safi et al. 1999, Fulcrand et al. 1996, He et al. 2012). These compounds can react with additional acetaldehyde, anthocyanins, and flavanols to generate polymeric-type structures that can create significant changes in wine sensory attributes (Atanasova et al. 2002, Fulcrand et al. 2004, He et al. 2012). In addition to acetaldehyde, other oxidation products such as pyruvic acid can react with anthocyanins to form stable colored structures named pyranoanthocyanins (Fulcrand et al. 2004). In addition to the polyphenols, acetaldehyde reacts with other components of wine. One example is the condensation reaction between acetaldehyde and glycerol leading to the formation of dioxolane and dioxane acetals (da Silva Ferreira et al. 2002). 
Preservative compounds used in wine production can exert their action by interfering at different steps of wine oxidation, and thereby inhibit the formation of oxidation products. Sulfur dioxide prevents oxidative spoilage by scavenging hydrogen peroxide (Danilewicz 2011, Danilewicz and Wallbridge 2010) and by reacting with quinones, reducing them to the catechol form (Saucier and Waterhouse 1999) or yielding sulfonates as addition products (Nikolantonaki and Waterhouse 2012). In addition, the sulfur-containing tripeptide glutathione (GSH) found in grapes has been suggested to provide a protective effect by acting as sacrificial nucleophiles for quinones (Nikolantonaki and Waterhouse 2012). Further, GSH reacts with $\mathrm{H}_{2} \mathrm{O}_{2}$ (Finley et al. 1981) and may slow the Fenton reaction. A recent review summarizes the impact of $\mathrm{GSH}$ in winemaking (Kritzinger et al. 2013), showing specific antioxidant effects in preserving thiols and preventing oxidation while noting that some inactive yeast preparations usable in winemaking are high in GSH. In the United States, GSH is not yet listed on materials available for winemaking (Code of Federal Regulations 2014).

Although some reports suggest that exogenous antioxidants could alter the effect of MOx treatment, only one study directly investigated the role of $\mathrm{SO}_{2}$ (Tao et al. 2007), and a marked effect of this preservative on the evolution of polyphenols was observed. No data are reported in the literature that investigates the effect of antioxidants on the impact of MOx concerning the development of the other processes involved in red wine oxidation such as oxygen consumption and acetaldehyde production.

The aim of this study was to evaluate the influence of $\mathrm{SO}_{2}$ and GSH on the outcome of MOx treatments, using a model system in which wines underwent MOx in small tanks (23 L). Two treatments, wines with low or high levels of $\mathrm{SO}_{2}$ and GSH, were compared during the MOx of a Cabernet Sauvignon wine. Numerous components were analyzed, including dissolved oxygen, free $\mathrm{SO}_{2}$, acetaldehyde, color, anthocyanins and derived pigments, tannin, and acetaldehyde acetals to assess, as broadly as possible, changes to the oxidation treatment.

\section{Materials and Methods}

Wine. The red wine was produced during the 2013 vintage with 91\% Cabernet Sauvignon and 9\% Petite Sirah. The wine was produced by E \& J Gallo Winery (Sonoma, CA). After the malolactic fermentation, the wine was centrifuged and microfiltered $(0.45 \mu)$ to remove residual yeasts before it was used for the experiment to avoid any microbial involvement in the processes to be examined. The base parameters (mean \pm standard deviation) of wine at the start of the experiment were: ethanol content $13.43 \pm 0.09 \% \mathrm{v} / \mathrm{v}, \mathrm{pH} 3.76 \pm 0.03$, titratable acidity $5.94 \pm 0.08 \mathrm{~g} / \mathrm{L}$ expressed as tartaric acid, residual sugars $0.40 \pm 0.01 \mathrm{~g} / \mathrm{L}$, malic acid $0.087 \pm 0.008 \mathrm{~g} / \mathrm{L}$, acetic acid $0.31 \pm 0.01 \mathrm{~g} / \mathrm{L}$, free $\mathrm{SO}_{2} 16.5 \pm 0.7 \mathrm{mg} / \mathrm{L}$, and total $\mathrm{SO}_{2} 38.5 \pm 0.7 \mathrm{mg} / \mathrm{L}$. The $\mathrm{pH}$ was measured using an Orion 5 Star (Thermo Scientific, Boston, MA). Ethanol was analyzed using an alcolyzer (Anton-Paar, Ashland, VA). Titratable acidity was determined by titration with a sodium hydroxide solution to $\mathrm{pH} 7.0$ (Iland et al. 2004). A photomet- ric measurement based on the formation or consumption of coenzyme nicotinamide adenine dinucleotide (NAD) or its reduced form of NADH was used to determine malic and acetic acids. For these analyses, a photometric analyzer Thermo Scientific Gallery (manufactured by Thermo Fisher Scientific Oy, Finland) was used. Free and total $\mathrm{SO}_{2}$ were determined using the aspiration method (Iland et al. 2004).

Experimental design. The effect of $\mathrm{MOx}, \mathrm{SO}_{2}$, and $\mathrm{GSH}$ addition on acetaldehyde and the main classes of wine phenolics was studied in a $2 \times 2 \times 2$ factorial design. Eight experimental wines were prepared in duplicate. Before treatments, the wines received an addition of potassium metabisulfite to result in a final concentration of free $\mathrm{SO}_{2}$ of $25 \mathrm{mg} / \mathrm{L}$ (Low addition) or of $65 \mathrm{mg} / \mathrm{L}$ (High addition). The same wines received or did not receive addition of $20 \mathrm{mg} / \mathrm{L}$ of GSH (ACROS Organics, Morris Plains, NJ). This protocol gave four matrix-related combinations, coded as follows: LL (Low $\mathrm{SO}_{2}$ $25 \mathrm{mg} / \mathrm{L}$, Low GSH as no addition); LH (Low $\mathrm{SO}_{2} 25 \mathrm{mg} / \mathrm{L}$, High GSH added $20 \mathrm{mg} / \mathrm{L}$ ); HL (High $\mathrm{SO}_{2} 65 \mathrm{mg} / \mathrm{L}$, Low GSH as no addition); and $\mathrm{HH}$ (High $\mathrm{SO}_{2} 65 \mathrm{mg} / \mathrm{L}$, High GSH added $20 \mathrm{mg} / \mathrm{L}$ ). Each wine was divided into two equal portions, one half of the wine underwent the MOx treatment, the other half of the wine was left for 30 days in a tank in the same condition of temperature as the microoxygenated wines and was considered the control. All treatments were conducted in duplicate; for example, there were two tanks holding LL wine with MOx treatment. Wines that underwent the MOx treatment were coded as: MLL (MOx, Low $\mathrm{SO}_{2} 25 \mathrm{mg} / \mathrm{L}$, Low GSH as no addition); MLH (MOx, Low $\mathrm{SO}_{2} 25 \mathrm{mg} / \mathrm{L}$, High GSH 20 mg/L); MHL (MOx, High SO 65 mg/L, Low $\mathrm{GSH}$ as no addition) and $\mathrm{MHH}\left(\mathrm{MOx}, \mathrm{High} \mathrm{SO}_{2} 65 \mathrm{mg} / \mathrm{L}\right.$, High GSH $20 \mathrm{mg} / \mathrm{L}$ ). Overall, sixteen $23 \mathrm{~L}$ tanks were used.

MOx system. All tanks used in the MOx experiment were made of stainless steel and included lid fittings and three entry points for (a) the $46 \mathrm{~cm}$ loop of tubing used as oxygen delivery system, (b) the sampling device, and (c) the dissolved oxygen detector (Figure 1). The three entry points and an additional exit for the oxygen delivery tubing were all located on the tank lid, which was purpose-built starting from a conventional tank lid in the lab. Conventional lids were used to hermetically close the control tanks that were not exposed to oxygen treatment. Both tanks and lids were presterilized.

Oxygen delivery system. Oxygen gas (Ox R Industrial Oxygen; Airgas, Woodland, CA) was delivered into the wine tanks under pressure using a fluorinated ethylene propylene tubing FEP-188x250 (Ozone Solutions, Inc., Hull, IA). The oxygen was delivered into the $23 \mathrm{~L}$ stainless tanks through a sterile ingress on the lid of the tank. Oxygen delivery was measured using a hydroalcoholic solution, assessing the increased oxygen concentration over two weeks.

Wine sampling system. The sampling system was designed to provide an aseptic sample avoiding both the loss of wine volatile compounds and introduction of air or contaminants (e.g., microorganisms). Samples were collected through a septum (Agilent Technologies, Inc., New Castle, DE) by sterilized syringes. During MOx treatment, the wines were sampled at $2,5,10,15,20,25$, and 30 days after MOx commenced for 
acetaldehyde, $\mathrm{SO}_{2}$, and phenolics analyses. The eight control wines were sampled only after 30 days of storage in tanks under the same temperature used for MOx treated wines.

Dissolved oxygen analyses. To measure dissolved oxygen (DO) in the wine while keeping the tank closed, a system including an NMR tube (Wilmad LabGlass, Vineland, NJ) fixed on the internal face of the lid with the bottom end immersed in the wine was used. A PreSens PST3 oxygen sensor (Nomacorc LLC, Zebulon, NC) for measurement of trace oxygen was placed on the external part of the flat bottom of the NMR tube in contact with wine. DO at bottling was measured by oxo-luminescence, using a Nomasense oxygen analyzer (Nomacorc SA, Thimister Clermont, Belgium). The Nomasense fiberoptic trace oxygen meter (FIBOX 3LCD trace V7) was inserted into the NMR tube, thus avoiding opening the tank. Measurements were taken one hour after filling the tanks and every day during MOx treatments. Recently, it has been shown that DO measurements were affected by several wine components (del Alamo-Sanza et al. 2014). However, in this study, we performed a comparative trial and the use of compensation values was not necessary.

MOx trial. Each tank was purged with nitrogen immediately prior to filling. A layer of nitrogen was maintained over the wine while it was transferred into the tanks. Before sealing, the headspace volume was displaced with nitrogen. To ensure consistency, all the tanks were kept in a thermostated room at $19.5 \pm 0.1^{\circ} \mathrm{C}$. Because MOx treatment can induce significant DO gradients (Nevares et al. 2010), each tank was continuously stirred using magnetic stirrers. An insulating plate was placed between the stirrers and the tanks to eliminate any heat transfer to the fluid. Oxygen was introduced at a rate of $15 \mathrm{~mL} / \mathrm{L} / \mathrm{month}$ by setting the oxygen pressure at $430 \mathrm{kPa}$. This value was chosen based on the results of previous replicate trials in which the oxygen was supplied to a hydroalcoholic solution in a sealed 23 L tank.

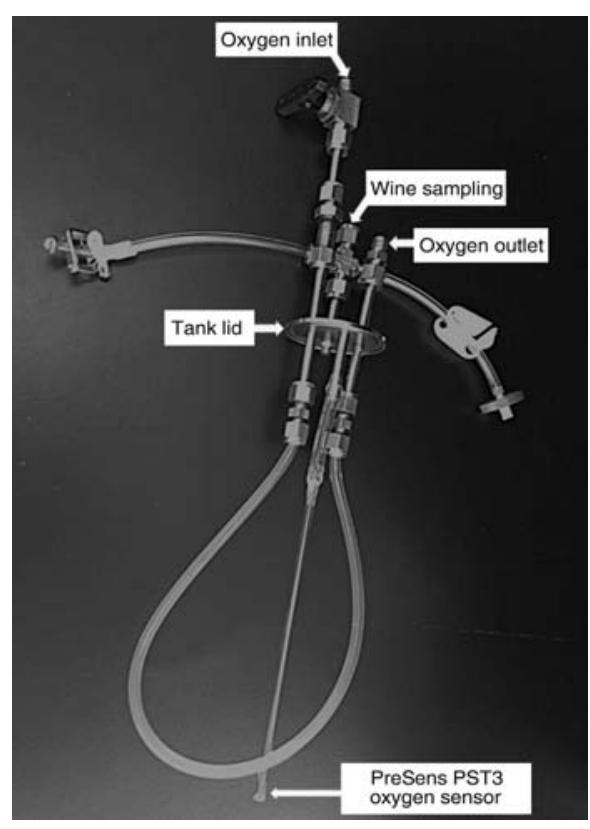

Figure 1 Stainless steel lid fittings.
$\mathrm{SO}_{2}$ measurements. The concentration of free and total $\mathrm{SO}_{2}$ was determined using the aspiration method (Iland et al. 2004).

Spectrophotometric analyses. Chromatic characteristics and spectrophotometric measures were determined using an Agilent $8453 \mathrm{UV}$-vis spectrophotometer (Agilent Technologies, Palo Alto, CA). Colorant intensity, abs420, abs520, abs620, and hue were evaluated according to the Glories methods (Glories 1984). Total anthocyanins and short polymeric pigments (SPP) were determined by the HarbertsonAdams assay (Harbertson et al. 2003). Briefly, pH changes allowed the evaluation of total anthocyanins while the large polymeric pigments (LPP) were obtained by combining analysis of supernatant obtained after protein precipitation using bovine serum albumin (Spectrum Chemical, Gardena, CA) with the bisulfite bleaching of pigments in wine. To determine vanillin reactive flavans (VRF), the method described by $\mathrm{Di}$ Stefano and Guidoni (1989) was scaled down and volumes were adjusted to decrease the consumption of organic solvents. The modified method required two $1.5 \mathrm{~mL}$ microfuge tubes for each sample. One hundred $\mu \mathrm{L}$ of wine was previously diluted 1 to 10 with methanol. The first tube was made by dispensing $125 \mu \mathrm{L}$ of diluted wine and then adding $750 \mu \mathrm{L}$ of a solution of vanillin ( $4 \%$ in methanol). After $5 \mathrm{~min}$, the tube was placed in cold water $\left(4^{\circ} \mathrm{C}\right)$ and $375 \mu \mathrm{L}$ of concentrated hydrochloric acid was added. After a 15 min incubation of the mixture at room temperature $\left(20^{\circ} \mathrm{C}\right)$, the absorbance was determined at $500 \mathrm{~nm}$. For the second tube, the procedure was the same except that $750 \mu \mathrm{L}$ of pure methanol was used instead of the solution of vanillin. The $500 \mathrm{~nm}$ absorbance of this tube was considered to be the blank. Concentrations were calculated as $(+)$-catechin $(\mathrm{mg} / \mathrm{L})$ by a calibration curve. Vanillin was purchased from Alfa Aesar (Ward Hill, MA).

High-performance liquid chromatography analyses of acetaldehyde. Acetaldehyde was analyzed using a newly modified method (Han et al. 2015). Briefly, wine sample aliquots $(100 \mu \mathrm{L})$ were dispensed to a vial, followed by addition of $20 \mu \mathrm{L}$ of freshly prepared $1120 \mathrm{mg} / \mathrm{L} \mathrm{SO}_{2}$ solution. Next, $20 \mu \mathrm{L}$ of $25 \%$ sulfuric acid was added, which was followed by $140 \mu \mathrm{L}$ of $8 \mathrm{~g} / \mathrm{L} 2,4-$ dinitrophenylhydrazine reagent. After mixing, the solution was allowed to react for $15 \mathrm{~min}$ at $65^{\circ} \mathrm{C}$ and then promptly cooled to room temperature. Analysis of carbonyl hydrazones was conducted by HPLC (HP 1100 series; Agilent Technologies, Wilmington, DE) coupled to a tandem mass spectrometer (HP 1100 series MSD; Agilent Technologies) equipped with an electrospray ionization interface for identification and UV detection for quantification and monitoring at $365 \mathrm{~nm}$. A ZORBAX Rapid Resolution HT, SB-C18 column $(1.8 \mu \mathrm{m}, 4.6 \times 100 \mathrm{~mm}$, Agilent Technologies) was used for separation. The chromatographic conditions were: sample injection volume, $15 \mu \mathrm{L}$; flow rate, $0.75 \mathrm{~mL} / \mathrm{min}$; column temperature, $35^{\circ} \mathrm{C}$; mobile phase solvents, (A) $0.5 \%$ formic acid in water and (B) acetonitrile; gradient elution protocol, $35 \% \mathrm{~B}$ to $60 \% \mathrm{~B}(\mathrm{t}=8 \mathrm{~min}$ ), $60 \% \mathrm{~B}$ to $90 \% \mathrm{~B}(\mathrm{t}=13 \mathrm{~min}$ ), $90 \% \mathrm{~B}$ to $95 \% \mathrm{~B}(\mathrm{t}=15 \mathrm{~min}, 2$-min hold), $95 \% \mathrm{~B}$ to $35 \% \mathrm{~B}(\mathrm{t}=17 \mathrm{~min}$, 4-min hold), total run time, $21 \mathrm{~min}$. Eluted peaks were compared with derivatized carbonyl standards. Data analysis and 
peak integration was performed using the Agilent Chemstation (A 09.03) software package.

Cyclic acetal analyses. Heterocyclic acetal isomers from glycerol and acetaldehyde were analyzed using a newly optimized method (Peterson et al. 2015). Wine sample aliquots $(2 \mathrm{~mL})$ were dispensed into vials $(19 \mathrm{~mm} \times 65 \mathrm{~mm})$ and spiked with synthesized deuterium-labeled acetal isomers $(25 \mu \mathrm{L}$ of $800 \mathrm{mg} / \mathrm{L}$ in water) as internal standards. Acetals were extracted twice with $1 \mathrm{~mL}$ of ethyl acetate by placing capped vials on a 14-19 $\mathrm{mm}$ foam tube holder attached to a vortex mixer. Samples were shaken for $10 \mathrm{~min}$, and the organic layers were combined and dried over sodium sulfate $(0.5-1 \mathrm{~g})$. Dried extracts were analyzed by GC-MS using an Agilent model $6890 \mathrm{~N}$ gas chromatograph coupled to a 5973 mass spectrometric detection system. Isomers were separated on a DB-WAX capillary column $(30 \mathrm{~m} \times 0.25 \mathrm{~mm}$ i.d., film thickness $0.5 \mu \mathrm{m})$. One $\mu \mathrm{L}$ of the sample extract was injected at $240^{\circ} \mathrm{C}$ in splitless mode with a purge flow of $40 \mathrm{~mL} / \mathrm{min}$ to the split vent at 2.0 $\mathrm{min}$. The oven temperature program was as a follows: $1 \mathrm{~min}$ at $40^{\circ} \mathrm{C}, 10^{\circ} \mathrm{C} / \mathrm{min}$ up to $80^{\circ} \mathrm{C}, 2^{\circ} \mathrm{C} / \mathrm{min}$ up to $150^{\circ} \mathrm{C}, 10^{\circ} \mathrm{C} / \mathrm{min}$ to $250^{\circ} \mathrm{C}$, and finally held at this temperature for $5 \mathrm{~min}$. The carrier gas was helium with a constant flow at $0.8 \mathrm{~mL} / \mathrm{min}$. Mass spectrometric conditions included electron impact with $70 \mathrm{eV}$, an ion source temperature of $150^{\circ} \mathrm{C}$, and an emission current of $200 \mu \mathrm{A}$. The mass selective detector (MSD) was operated in full scan $(\mathrm{m} / \mathrm{z} 50-150)$ for ion selection. The molecular $(\mathrm{m} / \mathrm{z}$ 117), quantitative $(\mathrm{m} / \mathrm{z} 103)$, and qualitative $(\mathrm{m} / \mathrm{z} 87 / 88)$ ions for the four glycerol acetal isomers were measured in selective ion monitoring mode (SIM). Quantitation of the deuterium-labeled acetal isomers was performed by measuring the $m / z 91$ and 92 ions in SIM.

HPLC analyses of monomeric and polymeric phenolics. HPLC separation and quantification of monomeric and polymeric phenolics was performed according to the Waterhouse et al. method (1999) as successively modified (Peng et al. 2002). Analyses were performed using a Hewlett Packard (Agilent Technologies) 1100 series high-performance liquid chromatograph equipped with a diode array detector coupled to Chemstation software 10.02 (Hewlett Packard, Waldbronn, Germany). An Agilent PLRP-S 100-Å reversed-phase polystyrene divinyl benzene column $(4.6 \times 150 \mathrm{~mm}, 3 \mu \mathrm{m}$ particle size) protected with a guard cartridge with the same packing material (PLRP-S, $5 \times 3 \mathrm{~mm}$ ) kept at $35^{\circ} \mathrm{C}$ was used as the stationary phase. The HPLC solvents were: solvent A, 1.5\% v/v ortho-phosphoric acid (EMP Chemicals, Gibbstown, NJ), and solvent B, consisting of $80 \%$ acetonitrile (HPLC grade, Honeywell, Muskegon, MI) with $20 \%$ of solvent A. The following gradient was established: 0 time conditions, B 6\%; 73 min, B 31\%; 78 min, B 62\%, staying constant until 86 min; 90 min, B $6 \%$. This zero-time solvent mixture was followed by a 15-min equilibrium period prior to injecting the next sample. The flow rate of the mobile phase was $1 \mathrm{~mL} / \mathrm{min}$. Twenty $\mu \mathrm{L}$ of wine or calibration standards were injected onto the column. All the samples were filtered through $0.20 \mu \mathrm{m} \mathrm{Mi-}$ croLiter PTFE membrane filters (Wheaton, NJ) into dark glass vials and immediately injected into the HPLC system. Detection was performed by monitoring the absorbance signals at
$520 \mathrm{~nm}$ for free native anthocyanins, pyranoanthocyanins, and polymeric anthocyanins. For calibration, the external standard method was used: the calibration curve was plotted for the malvidin-3-monoglucoside (Extrasynthese, Lyon, France) from the peak area. The anthocyanins and pigments concentrations were expressed as $\mathrm{mg} / \mathrm{L}$ of malvidin-3-monoglucoside. Polymeric tannins were quantified at $280 \mathrm{~nm}$ as $\mathrm{mg} / \mathrm{L}$ of $(+)$-catechin (Sigma, St. Louis, MO). Two calibration curves were obtained by injecting seven solutions (in triplicate) containing increasing concentrations of malvidin-3-monoglucoside and catechin. Calibration curves were characterized by a determination coefficient $\left(\mathrm{R}^{2}\right)>0.999$. The analyses of wine samples were performed in duplicate. The identification of monomeric and polymeric phenolics was made by comparing results with the retention times and chromatographic profiles reported by Peng et al. (2002) and with pyranoanthocyanins UV-vis spectra reported by Blanco-Vega et al. (2011). The content of monomeric and polymeric phenolics of red wine before $\mathrm{MOx}$ treatment is reported in Table 1.

Statistical analyses. Quantitative data relative to the phenolic compounds of the treated wines were compared using Fisher's least significant differences procedure. When the variances were not homogeneous, data were analyzed using Kruskall-Wallis test. When results of the Kruskal-Wallis test were significant $(p<0.05)$, the significance of between-group differences was determined by the Bonferroni-Dunn test $(5 \%$ significance level). Multifactorial ANOVA with third-order interactions was used to evaluate the relationships among factors. Differences of $p<0.05$ were considered significant. These analyses were performed using XLSTAT (version 2013.6.04, Addinsoft, Paris, France). All data are means of four values (2 experimental replicates $\times 2$ analytical replicates).

\section{Results and Discussion}

MOx trial. A comparison among the DO concentration of wines treated with MOx under the different experimental treatments is shown in Figure 2. Although the concentration of DO was strongly influenced by the content and type of antioxidant compounds used, a general trend for all wines

Table 1 Content of monomeric and polymeric phenolics of red wine before the microoxygenation treatment as measured by RP-HPLC.

\begin{tabular}{lr}
\hline Compound & Content (mg/L) \\
\hline Delphinidin 3-glucoside & $25.17 \pm 0.09$ \\
Petunidin 3-glucoside & $26.41 \pm 0.23$ \\
Peonidin 3-glucoside & $12.86 \pm 0.04$ \\
Malvidin 3-glucoside & $246.97 \pm 1.54$ \\
Delphinidin 3-(6"l-acetyl)-glucoside & $13.46 \pm 0.34$ \\
Vitisin A & $1.49 \pm 0.16$ \\
Vitisin B & $1.57 \pm 0.02$ \\
Peonidin 3-(6"-acetyl)-glucoside & $4.65 \pm 0.11$ \\
Malvidin 3-(6"-acetyl)-glucoside & $93.22 \pm 0.85$ \\
Peonidin 3-(6"-coumaroyl)-glucoside + & $23.92 \pm 0.56$ \\
Malvidin 3-(6"-coumaroyl)-glucoside & \\
Polymeric pigments & $68.14 \pm 3.54$ \\
Total anthocyanins & $525.27 \pm 4.45$ \\
Polymeric tannins & $695.82 \pm 20.82$ \\
\hline
\end{tabular}


can be observed. In the first three days of treatment, wines with a high content of GSH and/or $\mathrm{SO}_{2}$ showed no increase or a slight decrease in DO, suggesting that, at the beginning of MOx treatment, these preservatives result in an oxygen consumption rate comparable to the oxygen dissolution. Starting at day four, a slight increase of DO was detected for all tanks. Between 15 and 21 days, DO reached the maximum value for MLL, MLH, and MHL followed by a decrease, but that one was very rapid for MLL.

A decrease of free $\mathrm{SO}_{2}$ by aeration oxidation was detected during the treatment and, after about 20 days, concentrations fell below the limit of detection for wines MLL and MLH, which both had an initial free $\mathrm{SO}_{2}$ content of $25 \mathrm{mg} / \mathrm{L}$ (Figure 3). A similar trend for free $\mathrm{SO}_{2}$ has been reported during the introduction of similar quantities of oxygen in three different MOx experiments performed on Merlot (Tao et al. 2007) and Cabernet Sauvignon (Fell et al. 2007) wines. As expected, both free $\mathrm{SO}_{2}$ and bound $\mathrm{SO}_{2}$ reacted during $\mathrm{MOx}$ due to the partial release of the bound form (Table 2). Considering that the oxygen supplied during MOx is equivalent to $20 \mathrm{mg} / \mathrm{L}$, and that it would remove $\sim 80 \mathrm{mg} / \mathrm{L}$ of total $\mathrm{SO}_{2}$ if the $\mathrm{SO}_{2}$ reacted both with quinones and $\mathrm{H}_{2} \mathrm{O}_{2}$, the amounts of consumed total $\mathrm{SO}_{2}$ detected in this study confirm previous evidence that at least two mole equivalents of $\mathrm{SO}_{2}$ were consumed during wine oxidation (Danilewicz 2011, Danilewicz and Wallbridge 2010).

Here, the loss of free $\mathrm{SO}_{2}$ led to a very rapid decrease of DO. Thus, initially, for the first 15 days, higher quantities of GSH are associated with lower levels of DO, but when

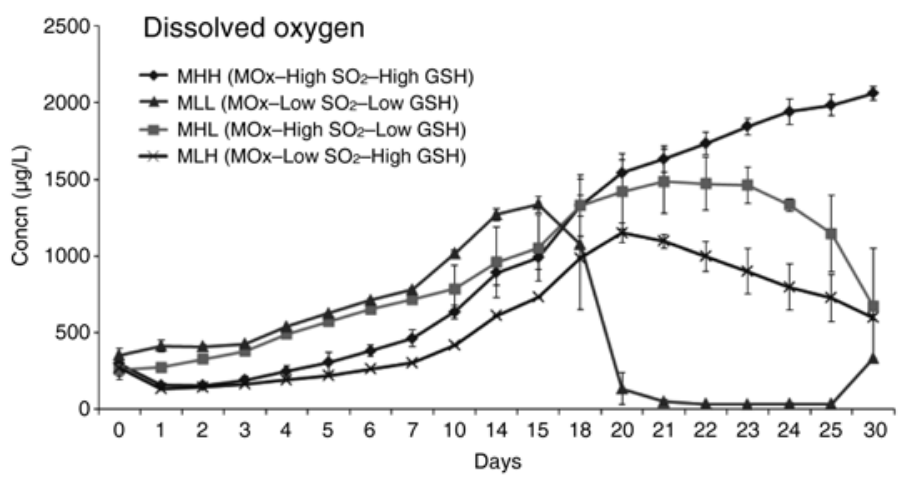

Figure 2 Dissolved oxygen changes for wines with different initial addition of $\mathrm{SO}_{2}$ and glutathione (GSH) during microoxygenation (MOx). the free $\mathrm{SO}_{2}$ is exhausted, oxygen consumption is greatly stimulated. The chemistry of non-enzymatic wine oxidation may explain these results (Figure 4). In a simplified reaction mechanism, the oxidation pathway can be summarized in two main phases. In a first step, wine hydroquinones undergo iron or copper catalyzed oxidation reactions, reducing oxygen to hydrogen peroxide and producing quinones. In the second step, iron (II) species react with hydrogen peroxide to form hydroxyl radicals in the Fenton reaction giving a large number of oxidation reactions with wine components. Therefore, the first step of wine oxidation can be considered to be governed by the chemistry of quinones while the second one by the presence of hydrogen peroxide. $\mathrm{SO}_{2}$ and $\mathrm{GSH}$ may affect both quinone and hydrogen peroxide reactivity but in an opposite manner. For quinones, the rate of reaction of oxygen is markedly accelerated by $\mathrm{SO}_{2}$ due to fact that quinone is reduced back to flavanol (Danilewicz et al. 2008, Danilewicz and Wallbridge 2010). In addition, both preservatives

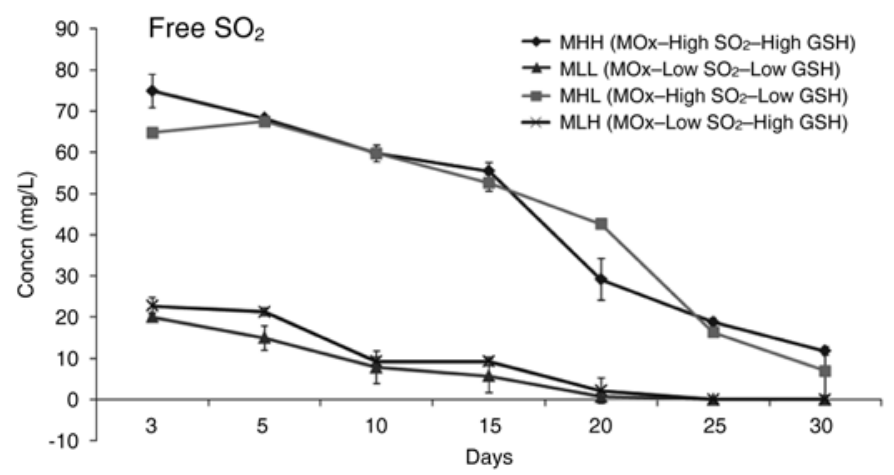

Figure 3 Levels of free $\mathrm{SO}_{2}$ for wines with different initial additions of $\mathrm{SO}_{2}$ and glutathione (GSH) during microoxygenation (MOx).

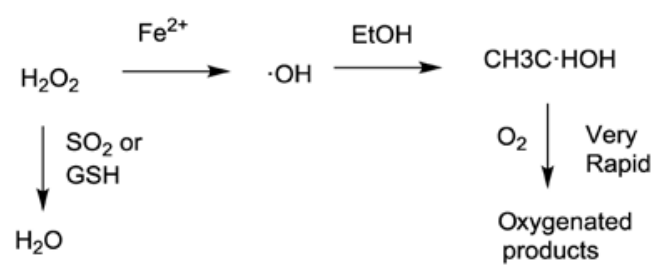

Figure 4 Mechanism for rapid oxygen loss when $\mathrm{SO}_{2}$ or glutathione (GSH) are depleted.

Table 2 Content of free, bound, and total $\mathrm{SO}_{2}$ of microoxygenated (MOx) wines.

\begin{tabular}{|c|c|c|c|}
\hline & Free $\mathrm{SO}_{2}(\mathrm{mg} / \mathrm{L})$ & Bound $\mathrm{SO}_{2}(\mathrm{mg} / \mathrm{L})$ & Total $\mathrm{SO}_{2}(\mathrm{mg} / \mathrm{L})$ \\
\hline \multicolumn{4}{|l|}{ Beginning of treatment ( 0 days) } \\
\hline MLL (MOx-Low $\mathrm{SO}_{2}$-Low GSHa) & $20.1 \pm 4.2$ & $31.7 \pm 2.1$ & $51.8 \pm 6.3$ \\
\hline MLH (MOx-Low $\mathrm{SO}_{2}-$ High GSH) & $22.8 \pm 2.5$ & $31.7 \pm 3.0$ & $54.5 \pm 5.5$ \\
\hline MHL (MOx-High $\mathrm{SO}_{2}-$ Low GSH) & $64.8 \pm 2.0$ & $53.3 \pm 2.3$ & $118.2 \pm 4.3$ \\
\hline $\mathrm{MHH}\left(\mathrm{MOx}-\mathrm{High} \mathrm{SO}_{2}-\mathrm{High} \mathrm{GSH}\right)$ & $74.9 \pm 0.0$ & $53.3 \pm 2.7$ & $128.3 \pm 2.7$ \\
\hline \multicolumn{4}{|l|}{ End of treatment (30 days) } \\
\hline MLL (MOx-Low SO $\mathrm{S}_{2}$-Low GSH) & $0.0 \pm 0.0$ & $9.7 \pm 2.0$ & $9.7 \pm 2.0$ \\
\hline MLH (MOx-Low $\mathrm{SO}_{2}-$ High GSH) & $0.0 \pm 0.0$ & $7.3 \pm 1.5$ & $7.3 \pm 1.5$ \\
\hline MHL (MOx-High SO $\mathrm{SO}_{2}$ Low GSH) & $6.9 \pm 5.9$ & $21.5 \pm 0.4$ & $28.4 \pm 5.9$ \\
\hline $\mathrm{MHH}\left(\mathrm{MOx}-\mathrm{High} \mathrm{SO}_{2}-\mathrm{High} \mathrm{GSH}\right)$ & $11.8 \pm 1.0$ & $16.3 \pm 0.5$ & $28.1 \pm 1.5$ \\
\hline
\end{tabular}

${ }^{\mathrm{a}} \mathrm{GSH}$ : glutathione. 
used, $\mathrm{SO}_{2}$ and $\mathrm{GSH}$, react with quinones (Nikolantonaki and Waterhouse 2012), shifting the oxygen consumption equilibrium toward the products, resulting in an increase in oxygen consumption (Danilewicz and Wallbridge 2010), explaining the lower levels of oxygen in the high $\mathrm{SO}_{2}$ solutions.

Looking at the Fenton reaction, sulfite is known to quickly react with hydrogen peroxide, thus competing with $\mathrm{Fe}(\mathrm{II})$, and reducing the formation of the hydroxyl radical. Previous studies conducted with spin trapping techniques showed that $\mathrm{SO}_{2}$ inhibits the formation of free radical species due to the Fenton reaction in a concentration dependent manner (Elias et al. 2009, Elias and Waterhouse 2010), supporting this theory. It appears that GSH may be able to slow wine oxidation reactions with hydrogen peroxide in a similar manner. This hypothesis is supported by numerous past studies that looked at the loss in the nutritional quality of foods during oxidations (Armstrong and Brechanan 1978, Winterbourn and Metodiewa 1999). Reaction of GSH with hydrogen peroxide was used as a model to study the oxidation of cysteine in proteins (Armstrong and Buchanan 1978). It is known that the rate of reaction for both preservatives with hydrogen peroxide is characterized by a strong $\mathrm{pH}$ dependence. In the $\mathrm{pH}$ range 2-6, lower $\mathrm{pH}$ values increase the rate of reaction for $\mathrm{SO}_{2}$ (Drexler et al. 1991), while the oxidation rate of GSH by hydrogen peroxide increases with increasing $\mathrm{pH}$ (Finley et al. 1981). However, taking into account the low amount of GSH used in this experiment and the high $\mathrm{O}_{2}: \mathrm{GSH}$ molar reaction ratio, it seems that the more relevant effect produced by GSH is due to other reactions than to its reaction with $\mathrm{H}_{2} \mathrm{O}_{2}$, likely due to its capability of reacting rapidly with quinones (Nikolantonaki and Waterhouse 2012) and other organic compounds such as catechin, hydroxycinnamic acids, and carbonyls involved in wine oxidation (Bouzanquet et al. 2012, Sonni et al. 2011b).

According to proposed chemical mechanisms involved, the behaviors detected during the MOx may be the results of several phenomena. During the first three days of treatment, the lower values of DO detected for MLH and MHH suggest that reactions involving quinones are dominant in determining oxygen consumption, and thus GSH accelerates consumption by rapidly reacting with quinones, probably acting as "oxidation promoting nucleophiles" (Danilewicz 2011). When both preservatives are no longer available, rapid consumption of oxygen occurs due to the production of radicals by the Fenton reaction, and it is these radicals that react most rapidly with oxygen.

In the MLL wines, after a few days during which the oxygen was almost all consumed, the DO started to increase. A similar trend for DO has been reported by Laurie et al. (2008) in an experiment conducted on red wine after malolactic fermentation completion. These results seem to indicate that each wine has a maximum capacity of oxygen uptake, and before reaching this limit, the quantity of oxygen consumed is limited only by the amount introduced. When oxygen-consuming reactants begin to be depleted, the oxidation reactions slow and oxygen starts to accumulate.

As observed in prior MOx studies, an increase in acetaldehyde has been detected in the later stages of MOx, as observed here for wines MLL, MLH, and MHL (Carlton et al. 2007, Fell et al. 2007). The acetaldehyde levels started to increase after 20 days of treatment and followed the order MLL $>>M L H>M H L$. This dramatic increase started contemporaneously with the rapid decrease in DO and when the content of $\mathrm{SO}_{2}$ was close to zero, and is thus an important clue to understanding the operative chemical reactions. This also reveals key indications of the role played by $\mathrm{SO}_{2}$ in regulating the production of acetaldehyde in MOx treatments by preventing the Fenton reaction (Figures 2 and 3). Herein, results agree with data reported in a previous experiment showing that the production of 1-hydroxyethyl radicals in an aerated wine model solution by Fenton reaction could be completely stopped when $\mathrm{SO}_{2}$ was present at $1000 \mu \mathrm{M}$ while lower concentrations $\left(500 \mu \mathrm{M} \mathrm{SO}_{2}\right)$ inhibited the production of radicals by $87.2 \%$ as compared with the control (Elias and Waterhouse 2010). Experiments performed on beer (Andersen et al. 2000) and wine (Elias et al. 2009) also showed a suppression of 1-hydroxyethyl radicals by $\mathrm{SO}_{2}$. The evidence that in the MHL treatment acetaldehyde coexists with free $\mathrm{SO}_{2}$ despite strong binding is consistent with previous findings by Schmidtke et al. (2011). However, this is the first observation that GSH can inhibit acetaldehyde production in wine oxidation during MOx. It is known that GSH binds acetaldehyde (Sonni et al. 2011b) and that oxidation of GSH yields several oxidation products when it reacts with hydrogen peroxide in aqueous solution at $\mathrm{pH}$ values close to that of wine (Finley et al. 1981). Thus, it seems possible that this molecule exerts a protective function in wine by several possible mechanisms: (i) scavenging hydrogen peroxide, (ii) by direct reaction with wine phenolics (Bouzanquet et al. 2012, Sonni et al. 2011a, 2011b) by way of quinones (Nikolantonaki and Waterhouse 2012), and (iii) binding acetaldehyde to a less extent with respect to $\mathrm{SO}_{2}$ (Sonni et al. 2011b). A synergic effect of $\mathrm{SO}_{2}$ and GSH is also not ruled out. More studies are necessary to better understand the role played by GSH in controlling the Fenton reaction. The effect of $\mathrm{SO}_{2}$ and GSH on the evolution of total anthocyanins and monomeric anthocyanins is reported in Figure 5A. As expected, a decline in total and monomeric anthocyanins was detected because they are involved in several reactions. They can: (1) combine or condense with acetaldehyde and other oxidation products, forming stable cycloaddition products (pyranoanthocyanidins); (2) participate in condensation reactions with other phenolic compounds or self-condense to give other more complex pigments; (3) produce polymeric anthocyanins from condensation reactions between anthocyanins and/or flavan-3-ols directly or mediated by aldehydes; and (4) disappear due to an oxidative mechanism involving direct reaction with peroxide and free radicals and/or through reactions with the oxidized components of the media to yield colorless or brown products (Fulcrand et al. 2004, He et al. 2012, Jackman et al. 1987).

$\mathrm{SO}_{2}$ exhibited a protective effect against the decline in free native anthocyanins, and the data suggests a small enhancement in anthocyanin levels as a result of $\mathrm{SO}_{2}$ treatment, perhaps by trapping acetaldehyde that had bound to anthocyanins (Drinkine et al. 2007). After 20 days, a smaller effect 
was detected for total anthocyanins, and in both instances the decline was more pronounced after 20 days of treatment when $\mathrm{SO}_{2}$ levels reached zero in MLL and MLH. A similar effect on anthocyanins in low $\mathrm{SO}_{2}$ wines during $\mathrm{MOx}$ has been reported by Tao et al. (2007) in which they detected a faster loss of total pigments after 40 days of treatment with an oxygen flow of $10 \mathrm{~mL} / \mathrm{L} / \mathrm{month}$. In an industry scale postmalolactic fermentation MOx trial performed on South African wines, the level of free anthocyanins decreased after 10 weeks of treatment with $3 \mathrm{mg} / \mathrm{L} / \mathrm{month}$ of oxygen (du Toit et al. 2006). For MLL and MLH wines, the more rapid loss of free anthocyanins was coincident with the increase of pyranoanthocyanins and polymeric pigments, observed after 20 days of treatment (Figure 5B). For MHH and MHL wines, no formation of new pigments during the treatment was observed, indicating that in these wines the anthocyanin stabilization reactions were inhibited by the higher levels of $\mathrm{SO}_{2}$. Comparing these data with the evolution of acetaldehyde (Figure 6), it seems that the formation of acetaldehyde and other likely carbonyls from the Fenton reaction is the limiting factor in color stabilization and $\mathrm{SO}_{2}$ is a major inhibitor. The evidence that a strong influence of $\mathrm{SO}_{2}$ and, to a lesser extent, of GSH, was observed is further confirmation that these compounds are very reactive in inhibiting the Fenton formation of aldehydes and that they also prevent reactions with anthocyanins by diverting the aldehydes to bound forms.

Apart from color stabilization, MOx is widely used in the wine industry to diminish tannin astringency more quickly than can be obtained by several months' barrel aging. Such changes are closely related to variations of a complex mixture of macromolecules constituting wine tannins with the formation of modified structures that can exhibit different organoleptic properties. In MLL and MLH wines, an increase of polymeric tannins by HPLC was measured (Figure 7). Recently it has been shown that under oxidative conditions, different reaction pathways such as intra- versus inter-molecular reactions of native proanthocyanidins occur, yielding high polymerized and branched tannins (Mouls and Fulcrand 2012, Vernhet et al. 2014). In addition, the formation of anthocyanin-ethyl-flavan-3-ol adducts (Cejudo-Bastante et al. 2011a) and of anthocyanins/tannins adducts (Fulcrand et al. 2004) can occur. The increase of polymeric tannins detected only for MLL and MLH wines suggest that reactions involving acetaldehyde such as the formation of ethyl bridged

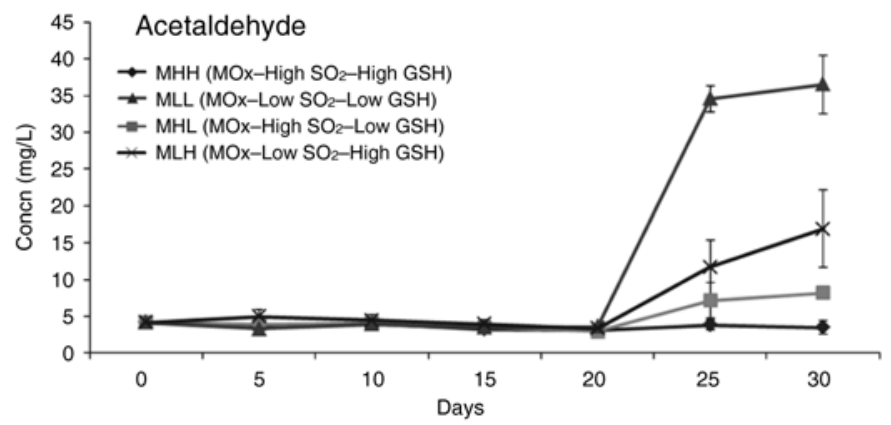

Figure 6 Levels of acetaldehyde for wines with different initial addition of $\mathrm{SO}_{2}$ and glutathione (GSH) during microoxygenation (MOx).
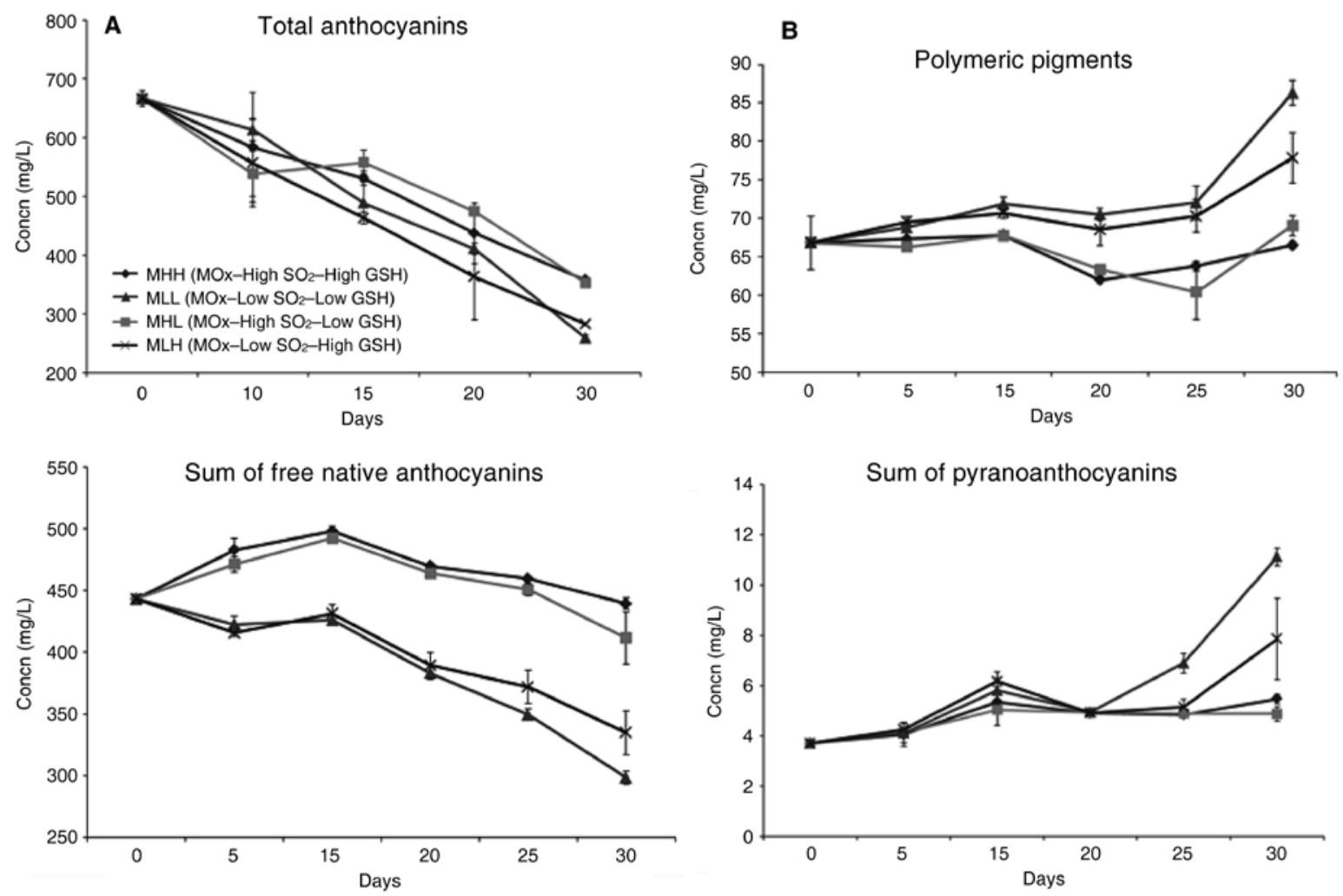

Figure 5 Effect of $\mathrm{SO}_{2}$ and glutathione (GSH) on the loss of total anthocyanins (Harbertson et al. 2003) and native anthocyanins (HPLC) (A) and the formation of polymeric pigments (Harbertson et al. 2003) and pyranoanthocyanins (HPLC) (B) during microoxygenation (MOx). 


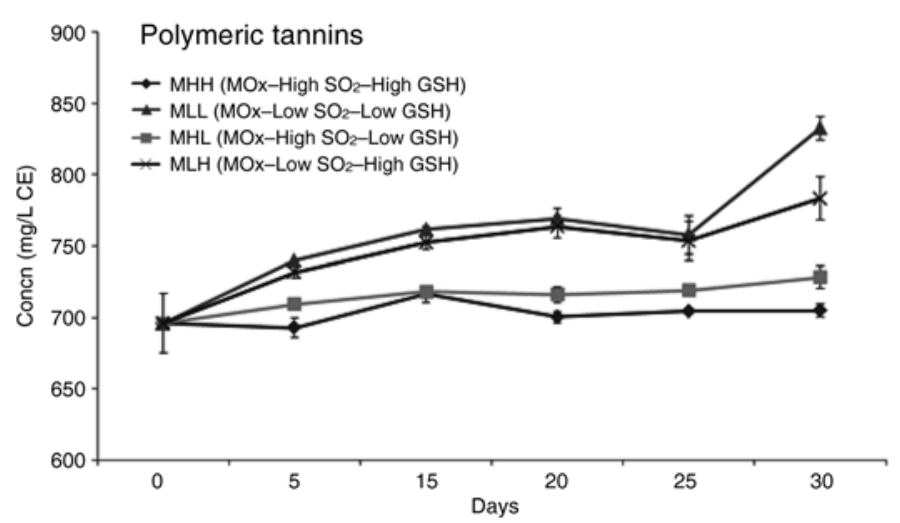

Figure 7 Effect of $\mathrm{SO}_{2}$ and glutathione (GSH) on the formation of polymeric tannins during microoxygenation (MOx). flavan-3-ols probably occurred. These data further support the occurrence of an accelerated oxidation of wine phenolics when acetaldehyde increases after $\mathrm{SO}_{2}$ levels reached zero. The evidence that the content of polymeric tannins is lower for MLH than MLL at the end of the MOx confirms the role played by GSH in the modulation of phenolics oxidation. This is consistent with previous results of Sonni et al. (2011b), suggesting a substantial impact of GSH on carbonylderived polymerization reactions in wine.

Effects on color parameters, tannin, and phenolic composition. Anthocyanins, anthocyanin-related red pigments, and polymeric tannins were affected by preservative treatments whether or not MOx was being applied (Table 3). A decrease of all native free anthocyanins with MOx was detected

Table 3 Effect of microoxygenation, $\mathrm{SO}_{2}$, and glutathione $(\mathrm{GSH})$ on monomeric and polymeric phenolics (mg/L) of red wine after 30 days of treatment measured by RP-HPLC.

\begin{tabular}{|c|c|c|c|c|}
\hline \multirow[b]{2}{*}{ Phenolics } & \multicolumn{4}{|c|}{ Control wines $^{a}$} \\
\hline & $\mathrm{HH}$ & HL & LH & LL \\
\hline Delphinidin 3-glucoside & $25.65 \pm 0.55 a^{b}$ & $25.31 \pm 0.17 \mathrm{a}$ & $21.89 \pm 0.10 b$ & $22.04 \pm 0.14 b$ \\
\hline Petunidin 3-glucoside & $27.46 \pm 0.52 \mathrm{a}$ & $27.28 \pm 0.17 \mathrm{a}$ & $23.33 \pm 0.15 b$ & $23.42 \pm 0.11 \mathrm{~b}$ \\
\hline Peonidin 3-glucoside & $13.19 \pm 0.29 a$ & $13.04 \pm 0.04 \mathrm{a}$ & $11.37 \pm 0.03 b$ & $11.28 \pm 0.05 b$ \\
\hline Malvidin 3-glucoside & $262.96 \pm 5.19 a$ & $260.94 \pm 1.73 \mathrm{a}$ & $222.96 \pm 2.43 b$ & $223.96 \pm 1.02 b$ \\
\hline Delphinidin 3-(6"-acetyl)-glucoside & $7.21 \pm 0.23 \mathrm{a}$ & $7.13 \pm 0.02 \mathrm{a}$ & $6.04 \pm 0.06 b$ & $5.91 \pm 0.06 b$ \\
\hline \multicolumn{5}{|l|}{$\begin{array}{l}\text { Pyr1 (unknown pyranoanthocyanins, } \\
\text { retention time, } 39.7 \mathrm{~min})^{\mathrm{c}}\end{array}$} \\
\hline Vitisin A & $2.88 \pm 0.06 c$ & $2.95 \pm 0.01 b$ & $3.27 \pm 0.00 \mathrm{a}$ & $3.28 \pm 0.02 \mathrm{a}$ \\
\hline Vitisin B & $1.26 \pm 0.09 \mathrm{~b}$ & $1.66 \pm 0.19 a$ & $0.92 \pm 0.06 \mathrm{c}$ & $0.89 \pm 0.04 c$ \\
\hline \multicolumn{5}{|l|}{$\begin{array}{l}\text { Pyr4 (unknown pyranoanthocyanins, } \\
\text { retention time, } 47.47 \mathrm{~min})^{d}\end{array}$} \\
\hline Peonidin 3-(6"-acetyl)-glucoside & $4.80 \pm 0.15 \mathrm{a}$ & $4.69 \pm 0.03 \mathrm{a}$ & $4.44 \pm 0.05 b$ & $4.30 \pm 0.05 c$ \\
\hline Malvidin 3-(6"-acetyl)-glucoside & $100.75 \pm 2.14 a$ & $100.15 \pm 0.54 \mathrm{a}$ & $84.09 \pm 0.56 b$ & $84.45 \pm 0.36 b$ \\
\hline $\begin{array}{l}\text { Peonidin 3-(6"-coumaroyl)-glucoside }+ \\
\text { Malvidin 3-(6"-coumaroyl)-glucoside }\end{array}$ & $30.90 \pm 0.68 \mathrm{a}$ & $30.94 \pm 0.30 \mathrm{a}$ & $24.43 \pm 0.33 c$ & $25.80 \pm 1.08 b$ \\
\hline Polymeric pigments & $63.93 \pm 1.28 \mathrm{a}$ & $63.46 \pm 0.88 \mathrm{a}$ & $61.35 \pm 3.32 a b$ & $59.98 \pm 1.79$ \\
\hline Total anthocyanins & $540.98 \pm 10.86 a$ & $537.54 \pm 2.12 a$ & $464.08 \pm 4.08 b$ & $465.31 \pm 1.33 b$ \\
\hline \multirow[t]{2}{*}{ Polymeric tannins } & $675.35 \pm 10.64 b$ & $674.18 \pm 6.78 b$ & $723.85 \pm 6.47 \mathrm{a}$ & $706.96 \pm 16.74 a$ \\
\hline & \multicolumn{4}{|c|}{ Microoxygenated wines $^{a}$} \\
\hline Phenolics & MHH & MHL & MLH & MLL \\
\hline Delphinidin 3-glucoside & $23.79 \pm 0.23 a$ & $22.72 \pm 0.89 a$ & $18.56 \pm 1.09 \mathrm{~b}$ & $16.66 \pm 0.28 c$ \\
\hline Petunidin 3-glucoside & $25.39 \pm 0.28 a$ & $23.91 \pm 1.16 b$ & $19.37 \pm 1.12 \mathrm{c}$ & $17.26 \pm 0.27 \mathrm{~d}$ \\
\hline Peonidin 3-glucoside & $12.30 \pm 0.18 a$ & $11.67 \pm 0.54 b$ & $9.94 \pm 0.36 \mathrm{c}$ & $9.04 \pm 0.14 d$ \\
\hline Malvidin 3-glucoside & $241.89 \pm 2.47 \mathrm{a}$ & $227.27 \pm 10.64 b$ & $186.86 \pm 9.63 \mathrm{c}$ & $167.44 \pm 2.92 \mathrm{~d}$ \\
\hline Delphinidin 3-(6"-acetyl)-glucoside & $6.76 \pm 0.03 \mathrm{a}$ & $6.33 \pm 0.34 b$ & $5.14 \pm 0.36 c$ & $4.47 \pm 0.11 \mathrm{~d}$ \\
\hline $\begin{array}{l}\text { Pyr1 (unknown pyranoanthocyanins, } \\
\text { retention time, } 39.7 \mathrm{~min})^{\mathrm{c}}\end{array}$ & & & & $2.23 \pm 0.25$ \\
\hline Vitisin A & $2.88 \pm 0.09 b$ & $2.70 \pm 0.19 b$ & $3.80 \pm 0.14 \mathrm{a}$ & $3.64 \pm 0.04 \mathrm{a}$ \\
\hline Vitisin B & $1.85 \pm 0.12 \mathrm{~d}$ & $1.43 \pm 0.10 \mathrm{c}$ & $2.03 \pm 0.11 b$ & $2.22 \pm 0.07 \mathrm{a}$ \\
\hline $\begin{array}{l}\text { Pyr4 (unknown pyranoanthocyanins, } \\
\text { retention time, } 47.47 \mathrm{~min})^{\mathrm{d}}\end{array}$ & & & & $0.81 \pm 0.13$ \\
\hline Peonidin 3-(6"-acetyl)-glucoside & $4.51 \pm 0.02 \mathrm{a}$ & $4.26 \pm 0.19 \mathrm{a}$ & $3.47 \pm 0.26 b$ & $2.93 \pm 0.08 c$ \\
\hline Malvidin 3-(6"-acetyl)-glucoside & $92.48 \pm 0.95 a$ & $85.77 \pm 5.30 b$ & $68.82 \pm 3.61 \mathrm{c}$ & $61.25 \pm 1.15 \mathrm{~d}$ \\
\hline $\begin{array}{l}\text { Peonidin 3-(6"-coumaroyl)-glucoside }+ \\
\text { Malvidin 3-(6"-coumaroyl)-glucoside }\end{array}$ & $27.00 \pm 0.45 \mathrm{a}$ & $24.38 \pm 2.13 b$ & $17.42 \pm 1.67 \mathrm{c}$ & $14.55 \pm 0.33 \mathrm{~d}$ \\
\hline Polymeric pigments & $66.54 \pm 0.52 c$ & $69.06 \pm 1.32 \mathrm{c}$ & $77.84 \pm 3.23 b$ & $86.31 \pm 1.62 \mathrm{a}$ \\
\hline Total anthocyanins & $505.39 \pm 5.14 a$ & $479.49 \pm 20.14 a b$ & $413.81 \pm 14.19 b$ & $383.13 \pm 2.95 c$ \\
\hline Polymeric tannins & $704.76 \pm 4.58 \mathrm{~d}$ & $728.16 \pm 8.12 \mathrm{c}$ & $783.25 \pm 15.28 b$ & $832.59 \pm 8.41 \mathrm{a}$ \\
\hline
\end{tabular}

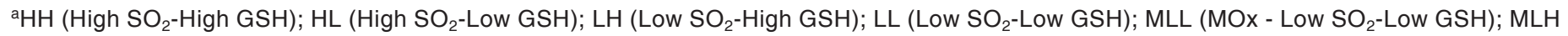
(MOx-Low $\mathrm{SO}_{2}$-High GSH); MHL (MOx-High SO $\mathrm{S}_{2}$-Low GSH); $\mathrm{MHH}$ (MOx-High SO $\mathrm{SO}_{2}$-High GSH).

bifferent letters indicate statistical differences $(p<0.05)$.

cPartially coeluted with Pyr2.

dPartially coeluted with Pyr3. 
in agreement with previous results (Cejudo-Bastante et al. 2011a, Gambuti et al. 2013). For each native anthocyanin the relative loss followed the order: $\mathrm{MLL}>\mathrm{MLH}>\mathrm{MHL}>\mathrm{MHH}$. The percentage of decrease was four times higher in MLL compared to $\mathrm{MHH}$ wines (e.g., for malvidin 3-glucoside, the percentage of decrease was $25 \%$ in MLL, $16 \%$ in MLH, $13 \%$ in MHL, and $8 \%$ in MHH). Therefore, it is possible to say that anthocyanins are protected by both $\mathrm{SO}_{2}$ and $\mathrm{GSH}$, and for the first time a specific protective role has been demonstrated for GSH. The sensitivity to MOx is different for each anthocyanin and the acylated ones were more affected, suggesting a possible role of copigmentation in these reactions (Boulton 2001). Because malvidin-3-O-glucoside and peonidin-3-Oglucoside reacted as much as the others confirms the hypothesis that the key reactions with aldehydes and ketones are not on the B-ring but on the C-and A-rings.

Wines in the treatments that initially contained the lower level of $\mathrm{SO}_{2}, 25 \mathrm{mg} / \mathrm{L}$ (MLL and MLH), ended up with higher content of pyranoanthocyanins. However, Asenstorfer et al. (2003) showed that higher $\mathrm{SO}_{2}$ amounts added before alcoholic fermentation resulted in wines with higher content of vitisin A. This apparent contradiction can be explained by considering alternate sources of pyruvic acid. In a post-malolactic fermentation trial, as in this experiment, it is likely that pyruvate is formed by chemical oxidation of malic acid, and $\mathrm{SO}_{2}$ inhibits this process by limiting the Fenton reaction. However, during fermentation, pyruvic acid is produced by microorganisms and its concentration in wine is enhanced through the formation of a weak bisulfite-addition complex. In this latter case, more $\mathrm{SO}_{2}$ results in a greater accumulation of pyruvic acid through the shift of free and bound $\mathrm{SO}_{2}$ when the wine is subsequently oxidized. Additionally, compared to $\mathrm{MHH}$, vitisin B was increased by about $20 \%$ in MLL and MLH wines, likely due to the increased formation of acetaldehyde in these wines. In concurrence with these results, Cejudo-Bastante et al. (2011a) showed that an oxygen addition increased the concentrations of anthocyanin-ethylflavan-3-ols, anthocyanin-ethyl-B-type-procyanidins, and
B-type vitisins, in particular just after the MOx treatment. In addition, the MOx treatment resulted in an increase in polymeric pigments and tannins, and the presence of preservatives limit their formation in agreement with observations of Bakker et al. (1998), showing a clear effect of $\mathrm{SO}_{2}$ on the polymerization processes. Thus, the observations noted here concur with others in that the MOx treatment increases the yield of stabilized pigment from carbonyl reactions, while sulfite decreases their yield.

As previously observed by other authors (Cejudo-Bastante et al. 2011b), the addition of oxygen results in a decrease of color intensity with an increase of absorbance at $420 \mathrm{~nm}$ and hue (Table 4). In addition, some authors observed an increase of color intensity (CI) several months after the treatment (Cano-López et al. 2008, Gambuti et al. 2013), suggesting that time dependent reactions create a general hyperchromic effect in microoxygenated wines. As expected, a bleaching effect of $\mathrm{SO}_{2}$ was observed as demonstrated by the lower values of $520 \mathrm{~nm}$ absorbance and CI for wines with higher $\mathrm{SO}_{2}$. Further supporting these results, total anthocyanins as measured by the Harbertson-Adams assay are reduced by MOx treatment, and preserved by $\mathrm{SO}_{2}$ addition (Table 5). Oxygen addition also resulted in a decrease of SPP, perhaps because they were converted to higher high molecular weight structures by cross-linking reactions.

Oxidation reduces VRF, while both $\mathrm{SO}_{2}$ and $\mathrm{GSH}$ reduce these losses. These results can be interpreted by chemical reactions between oxidation products such as acetaldehyde with the $\mathrm{C} 8$ and $\mathrm{C} 6$ positions on the A-ring of flavanols (Fulcrand et al. 2004). The vanillin assay uses the aldehyde vanillin, and it reacts with the same positions on the flavanol A-ring to produce a colored product (Hagerman et al. 1997). Therefore, the measurement by VRF may be considered an indirect, inverse measure of the oxidative polymerization of flavanols. Thus, the VRF assay may well be a good marker for tannin oxidation. By the same analysis, the reduction in tannin is due at least in part to acetaldehyde bridging reactions that inhibit protein binding.

Table 4 Effect of microoxygenation, $\mathrm{SO}_{2}$, and glutathione (GSH) on chromatic characteristics of red wine after 30 days of treatment.

\begin{tabular}{|c|c|c|c|c|c|}
\hline Treatment $^{a}$ & $\begin{array}{c}\text { Absorbance } \\
(420 \mathrm{~nm})\end{array}$ & $\begin{array}{c}\text { Absorbance } \\
(520 \mathrm{~nm})\end{array}$ & $\begin{array}{c}\text { Absorbance } \\
(620 \mathrm{~nm})\end{array}$ & $\mathrm{CI}^{\mathrm{b}}$ & Hue \\
\hline \multicolumn{6}{|c|}{ Control wines } \\
\hline LL & $5.83 \pm 0.02 \mathrm{~A}^{\mathrm{c}}$ & $9.22 \pm 0.02 \mathrm{~A}$ & $2.86 \pm 0.01 \mathrm{~A}$ & $17.91 \pm 0.05 \mathrm{~A}$ & $0.63 \pm 0.00 \mathrm{C}$ \\
\hline LH & $5.83 \pm 0.06 \mathrm{~A}$ & $9.16 \pm 0.05 \mathrm{~A}$ & $2.84 \pm 0.01 \mathrm{~A}$ & $17.83 \pm 0.12 \mathrm{~A}$ & $0.64 \pm 0.00 \mathrm{~B}$ \\
\hline $\mathrm{HL}$ & $5.41 \pm 0.06 \mathrm{~B}$ & $8.40 \pm 0.10 \mathrm{~B}$ & $2.67 \pm 0.03 \mathrm{~B}$ & $16.48 \pm 0.18 \mathrm{~B}$ & $0.64 \pm 0.00 \mathrm{~A}$ \\
\hline $\mathrm{HH}$ & $5.44 \pm 0.05 \mathrm{~B}$ & $8.40 \pm 0.06 \mathrm{~B}$ & $2.67 \pm 0.01 \mathrm{~B}$ & $16.51 \pm 0.11 \mathrm{~B}$ & $0.65 \pm 0.00 \mathrm{~A}$ \\
\hline \multicolumn{6}{|c|}{ Microoxygenaated wines } \\
\hline MLL & $5.75 \pm 0.04 \mathrm{~A}$ & $7.77 \pm 0.03 \mathrm{~A}$ & $2.48 \pm 0.01 \mathrm{~A}$ & $15.99 \pm 0.06 \mathrm{~A}$ & $0.74 \pm 0.00 \mathrm{~A}$ \\
\hline MLH & $5.72 \pm 0.07 \mathrm{~A}$ & $7.71 \pm 0.05 \mathrm{~A}$ & $2.44 \pm 0.03 \mathrm{~A}$ & $15.87 \pm 0.14 \mathrm{AB}$ & $0.74 \pm 0.00 \mathrm{~A}$ \\
\hline MHL & $5.62 \pm 0.15 \mathrm{~A}$ & $7.71 \pm 0.14 \mathrm{~A}$ & $2.35 \pm 0.05 \mathrm{~B}$ & $15.68 \pm 0.35 B$ & $0.73 \pm 0.01 \mathrm{~B}$ \\
\hline $\mathrm{MHH}$ & $5.42 \pm 0.01 \mathrm{~B}$ & $7.47 \pm 0.03 \mathrm{~B}$ & $2.27 \pm 0.00 \mathrm{C}$ & $15.15 \pm 0.03 \mathrm{C}$ & $0.72 \pm 0.00 \mathrm{~B}$ \\
\hline
\end{tabular}

aLL (Low SO2-Low GSH); LH (Low SO2-High GSH); HL (High SO2-Low GSH); HH (High SO2-High GSH); MLL (MOx-Low SO ${ }_{2}$-Low GSH); MLH (MOx-Low SO2-High GSH); MHL (MOx-High SO2-Low GSH); MHH (MOx-High SO2-High GSH).

${ }^{\mathrm{b}} \mathrm{Cl}$, Color intensity.

cUpper-case letters (A, B, C) used to compare among wines in each group (control and microoxygenated) treated with low and high levels of GSH and $\mathrm{SO}_{2}$. Different letters indicate statistical differences $(p<0.05)$. 
In this study, all the variables tested had the ability to affect the main phenolic parameters linked to wine evolution: the sum of free anthocyanins and pyranoanthocyanins and the content of polymeric phenolics (Table 6). Among the factors, MOx had the greatest effect. It generally resulted in wines with a higher content of pyranoanthocyanins, more polymers, and less free anthocyanins $(p<0.001)$. However, the added $\mathrm{SO}_{2}$ and, to a lesser extent, $\mathrm{GSH}$, both had an opposite effect on these parameters, resulting in protection of wine from oxidation and polymerization reactions. Apart from the sum of free anthocyanins, differences in interactions among all the variables considered were statistically significant, indicating that both $\mathrm{SO}_{2}$ and GSH modulated MOx. Therefore, for the first time, an important influence of GSH on red wine pigments and on the formation of polymeric tannins in red wine was demonstrated.

Effects on acetals. The concentrations of the acetaldehyde-glycerol acetals have been correlated to the aging of

Table 5 Effect of one month microoxygenation (MOx; $30 \mathrm{mg} \mathrm{O}$ ), $\mathrm{SO}_{2}$, and glutathione (GSH) on anthocyanins, SPP pigments (Harbertson et al. 2003), and vanillin reactive flavans of red wine.

\begin{tabular}{|c|c|c|c|}
\hline Treatment $^{\mathrm{a}}$ & $\begin{array}{c}\text { Anthocyanins } \\
\text { (mg/L) }\end{array}$ & SPP $^{b}$ & $\begin{array}{c}\text { VRF } \\
(\mathrm{mg} / \mathrm{L} \text { of } \mathrm{CE})^{\mathrm{c}}\end{array}$ \\
\hline \multicolumn{4}{|c|}{ Control wines } \\
\hline LL & $452.9 \pm 3.0 C^{d}$ & $1.26 \pm 0.01 \mathrm{~B}$ & $816 \pm 15 A$ \\
\hline $\mathrm{LH}$ & $446.4 \pm 4.3 \mathrm{D}$ & $1.28 \pm 0.02 \mathrm{~A}$ & $782 \pm 37 \mathrm{AB}$ \\
\hline $\mathrm{HL}$ & $511.9 \pm 4.9 \mathrm{~B}$ & $1.23 \pm 0.01 \mathrm{C}$ & $726 \pm 33 \mathrm{~B}$ \\
\hline $\mathrm{HH}$ & $518.7 \pm 2.6 \mathrm{~A}$ & $1.25 \pm 0.01 \mathrm{~B}$ & $792 \pm 25 \mathrm{AB}$ \\
\hline \multicolumn{4}{|c|}{$\begin{array}{l}\text { Microoxygenated } \\
\text { wines }\end{array}$} \\
\hline MLL & $259.4 \pm 5.4 \mathrm{C}$ & $1.22 \pm 0.01 \mathrm{~A}$ & $621 \pm 18 \mathrm{~B}$ \\
\hline MLH & $283.1 \pm 2.0 \mathrm{~B}$ & $1.08 \pm 0.01 \mathrm{~A}$ & $625 \pm 9 \mathrm{~B}$ \\
\hline MHL & $353.4 \pm 3.9 \mathrm{~A}$ & $1.04 \pm 0.00 \mathrm{~B}$ & $798 \pm 18 \mathrm{AB}$ \\
\hline $\mathrm{MHH}$ & $358.1 \pm 3.3 \mathrm{~A}$ & $1.04 \pm 0.00 \mathrm{~B}$ & $892 \pm 22 A$ \\
\hline
\end{tabular}

aLL (Low SO $\mathrm{S}_{2}$-Low GSH); LH (Low SO ${ }_{2}$-High GSH); HL (High $\mathrm{SO}_{2}$-Low $\mathrm{GSH}$ ); $\mathrm{HH}$ (High $\mathrm{SO}_{2}$-High GSH); MLL (MOx-Low $\mathrm{SO}_{2}$-Low GSH); $\mathrm{MLH}$ (MOx-Low $\mathrm{SO}_{2}$-High GSH); $\mathrm{MHL}$ (MOx-High $\mathrm{SO}_{2}$-Low GSH); $\mathrm{MHH}\left(\mathrm{MOx}-\mathrm{High} \mathrm{SO}_{2}\right.$-High GSH).

bSPP, short polymeric pigments.

'VRF, vanillin reactive flavans expressed as $\mathrm{mg} / \mathrm{L}$ of catechin equivalent (CE).

dUpper-case letters (A, B, C) are used to compare among wines in each group (control and microoxygenated) treated with low and high levels of $\mathrm{GSH}$ and $\mathrm{SO}_{2}$. Different letters indicate statistical differences $(p<0.05)$. a wine (da Silva Ferreira et al. 2002), indicating their connection with wine oxidation. Due to the formation of acetaldehyde through non-enzymatic oxidation of ethanol, these compounds are expected to increase in response to continuous oxygen exposure. The concentrations of the four isomers cis- and trans-1,3-dioxane and cis- and trans-1,3-dioxolane in the experimental wines are reported in Table 7. A subset of this data was previously reported with the method on the acetal analysis (Peterson et al. 2015). Higher values for all the acetal isomers were detected in wines that underwent the MOx treatment and particularly those not protected by $\mathrm{SO}_{2}$. Microoxygenated wines treated with high levels of $\mathrm{SO}_{2}(\mathrm{MHH}$ and MHL) contained comparable acetal concentrations to control wines, demonstrating the antioxidant properties of $\mathrm{SO}_{2}$. Da Silva Ferreira et al. (2002) observed a similar effect of $\mathrm{SO}_{2}$ on the evolution of these acetals during the storage of a port wine and model solutions. The authors added $\mathrm{SO}_{2}$ prior to barrel aging the samples. They ascribed the results to the binding of $\mathrm{SO}_{2}$ to acetaldehyde, thus inhibiting the acetylization reaction. In our experiment, the effects of $\mathrm{SO}_{2}$ and, to a lesser extent GSH, were also due to their activity in inhibiting the production of acetaldehyde during $\mathrm{MOx}$ or binding after production. A difference in the relative abundance of the dioxane isomers versus dioxolane isomers was detected in both oxygenated and control wine samples. The total content of the 6-membered acetal rings (dioxanes) were found to be the most abundant isomers in the non-oxygenated wines, while the introduction of oxygen to the wines resulted in acetal contents dominated by the 5 -membered acetal rings (dioxolanes). This inversion of isomer abundances was most evident in microoxygenated samples containing low levels of $\mathrm{SO}_{2}$ and GSH. The data confirms that the 5-membered rings are more kinetically stable and thus formed at a faster rate under conditions of rapid oxidation. In control wine samples, the isomers are able to equilibrate to a mixture dominated by $c i s$-1,3-dioxane (and dioxanes in general) due to its higher thermodynamic stability (Aksens and Albriktsen 1966). Thus, a higher concentration of the dioxolane isomers in a given wine sample indicates continuous high oxygen exposure (MOx) while a higher cisdioxane content indicates that the acetal isomers have reached equilibrium due to low oxidative conditions. The results from the acetal analysis of MOx wine samples confirm that these compounds are good markers of oxidation, most notably in techniques involving consistent additions of oxygen to wine

\begin{tabular}{|c|c|c|c|c|c|c|c|c|}
\hline Treatment $^{\mathrm{a}}$ & $\begin{array}{c}\Sigma \text { Free } \\
\text { anthocyanins }\end{array}$ & $P$ value $^{\text {b }}$ & $\begin{array}{c}\Sigma \text { Pyrano- } \\
\text { anthocyanins }\end{array}$ & $P$ value $^{\mathrm{b}}$ & $\begin{array}{l}\text { Polymeric } \\
\text { pigments }\end{array}$ & $P$ value $^{\mathrm{b}}$ & $\begin{array}{c}\text { Polymeric } \\
\text { tannins }\end{array}$ & $P$ value $^{\mathrm{b}}$ \\
\hline $\mathrm{SO}_{2}$ & 268.98 & $* * *$ & 547.09 & $* * *$ & 216.62 & $* * *$ & 342.26 & $* * *$ \\
\hline GSH & 20.11 & $* * *$ & 15.16 & $* *$ & 32.06 & $* * *$ & 54.13 & $* * *$ \\
\hline MOx & 341.33 & $* * *$ & 535.42 & $* * *$ & 489.39 & $* * *$ & 278.89 & $* * *$ \\
\hline $\mathrm{SO}_{2} \times \mathrm{GSH}$ & 0.35 & ns & 20.71 & $* * *$ & 9.39 & ** & 6.88 & * \\
\hline $\mathrm{SO}_{2} \times \mathrm{MOx}$ & 16.34 & ** & 727.32 & $* * *$ & 206.48 & $* * *$ & 44.36 & $* * *$ \\
\hline MOx x GSH & 16.52 & ** & 15.61 & $* *$ & 14.17 & ** & 28.02 & $* * *$ \\
\hline
\end{tabular}

a GSH, glutathione; MOx, microoxygenation.

${ }^{\mathrm{b}}, p<0.05 ;{ }^{* *}, p<0.01 ;{ }^{* *}, p<0.001$; ns, not significant. 
Table 7 Effect of microoxygenation (MOx), $\mathrm{SO}_{2}$, and glutathione (GSH) on acetaldehyde-glycerol acetals (mg/L) after 30 days of treatment as measured by GC-MS.

\begin{tabular}{|c|c|c|c|c|}
\hline Treatment $^{\mathrm{a}}$ & $\begin{array}{c}\text { cis-5-Hydroxy-2- } \\
\text { methyl-1.3-dioxane }\end{array}$ & $\begin{array}{l}\text { trans-5-Hydroxy-2- } \\
\text { methyl-1.3-dioxane }\end{array}$ & $\begin{array}{l}\text { cis-4-Hydroxymethyl-2- } \\
\text { methyl-1.3-dioxolane }\end{array}$ & $\begin{array}{c}\text { trans-4-Hydroxymethyl-2- } \\
\text { methyl-1.3-dioxolane }\end{array}$ \\
\hline \multicolumn{5}{|c|}{ Control wines } \\
\hline $\mathrm{HH}$ & $0.332 \pm 0.016$ & $0.133 \pm 0.0029$ & $0.163 \pm 0.016$ & $0.161 \pm 0.0023$ \\
\hline $\mathrm{HL}$ & $0.328 \pm 0.0024$ & $0.133 \pm 0.0019$ & $0.159 \pm 0.0010$ & $0.157 \pm 0.0014$ \\
\hline LH & $0.333 \pm 0.0054$ & $0.136 \pm 0.0024$ & $0.169 \pm 0.0017$ & $0.164 \pm 0.0031$ \\
\hline LL & $0.330 \pm 0.0028$ & $0.133 \pm 0.0022$ & $0.167 \pm 0.0029$ & $0.160 \pm 0.0021$ \\
\hline \multicolumn{5}{|c|}{ Microoxygenated wines } \\
\hline $\mathrm{MHH}$ & $0.440 \pm 0.0051$ & $0.176 \pm 0.0090$ & $0.354 \pm 0.0029$ & $0.267 \pm 0.0030$ \\
\hline $\mathrm{MHL}$ & $0.619 \pm 0.0080$ & $0.255 \pm 0.0060$ & $0.531 \pm 0.0064$ & $0.405 \pm 0.049$ \\
\hline MLH & $0.843 \pm 0.015$ & $0.323 \pm 0.0070$ & $0.708 \pm 0.011$ & $0.543 \pm 0.0059$ \\
\hline MLL & $1.29 \pm 0.019$ & $0.493 \pm 0.011$ & $1.30 \pm 0.023$ & $0.923 \pm 0.017$ \\
\hline
\end{tabular}

aHH (High SO ${ }_{2}$-High GSH); HL (High SO 2 -Low GSH); LH (Low SO ${ }_{2}$-High GSH); LL (Low SO ${ }_{2}$-Low GSH); MHH (MOx-High SO ${ }_{2}-\mathrm{High} \mathrm{GSH}$ ); MHL (MOx-High $\mathrm{SO}_{2}$-Low GSH); MLH (MOx-Low $\mathrm{SO}_{2}$-High GSH); MLL (MOx-LowSO - -Low GSH).

samples. Although the sum of four acetals do not exceed the sensory threshold $(100 \mathrm{mg} / \mathrm{L})$, a potential future impact of these compounds on wine aroma could occur if adequate oxidation occurs during aging (da Silva Ferreira et al. 2002, Martins et al. 2013). These substances have a sensory character of old port-like odor, and their concentration is correlated with barrel aging of port (da Silva Ferreira et al. 2002). Because acetaldehyde is the major product of the Fenton reaction, a determination of the accumulated formation of acetaldehyde and its products in a wine may be considered a marker of the oxidative evolution of a wine (Carlton et al. 2007).

\section{Conclusion}

This study provides clear evidence for a strong link between levels of $\mathrm{SO}_{2}$ and GSH in wine and reduced development of oxidation by-products during MOx treatment. The loss of free $\mathrm{SO}_{2}$ during MOx led to a dramatic acceleration of wine oxidation, signaled by a rapid loss of DO. This is likely due to the efficient consumption of oxygen by the Fenton reaction as suggested by a concomitant increase in acetaldehyde. The simultaneous increase in a series of other oxidation products linked to the presence of acetaldehyde, such as pyranoanthocyanins, polymeric pigments, and acetals further support the observation of accelerating oxidation.

A strong relationship between the appearance of various oxidation products and the loss of DO during MOx suggests that $\mathrm{DO}$, and/or free $\mathrm{SO}_{2}$ may be useful parameters to monitor the rate of oxidation reactions induced by the MOx process. GSH also played a very influential role in most of the parameters measured and a synergistic effect was observed in combination with $\mathrm{SO}_{2}$. Wines with reduced $\mathrm{SO}_{2}$ but added GSH showed an intermediate degree of oxidation, with enhanced production of stable phenolics but reduced production of acetals. In addition, GSH appeared to mitigate the loss of $\mathrm{DO}$ when $\mathrm{SO}_{2}$ was depleted, suggesting that the consumption of peroxide in the Fenton reaction is reduced. This could arise from GSH reduction of peroxide, providing another tool to manage MOx. Therefore, the use of GSH to modulate red wine evolution during oxidative treatments or perhaps also during aging may be an interesting complement to $\mathrm{SO}_{2}$ use; further studies could help develop usage protocols to provide winemakers with some direction on how to use various combinations of these two preservatives.

\section{Literature Cited}

Aksnes, G., and P. Albriktsen. 1966. Studies of intramolecular hydrogen bonding in cyclic acetal isomers of glycerol. Acta Chem. Scand. 20:1330-1334.

Andersen, M.L., H. Outtrup, and L.H. Skibsted. 2000. Potential antioxidants in beer assessed by ESR spin trapping. J. Agric. Food Chem. 48:3106-3111.

Arapitsas, P., M. Scholz, U. Vrhovsek, S. Di Blasi, A.B. Bartolini, D. Masuero, D. Perenzoni, A. Rigo, and F. Mattivi. 2012. A metabolomic approach to the study of wine micro-oxygenation. PLoS ONE 7:e37783.

Armstrong, D.A., and J.D. Buchanan. 1978. Reactions of $\mathrm{O}_{2}^{-}, \mathrm{H}_{2} \mathrm{O}_{2}$ and other oxidants with sulfhydryl enzymes. Photochem. Photobial. 28:743-755.

Asenstorfer, R.E., A.J. Markides, P.G. Iland, and G.P. Jones. 2003. Formation of vitisin A during red wine fermentation and maturation. Aust. J. Grape Wine Res. 9:40-46.

Atanasova, V., H. Fulcrand, V. Cheynier, and M. Moutounet. 2002. Effect of oxygenation on polyphenol changes occurring in the course of wine-making. Anal. Chim. Acta 458:15-27.

Bakker, J., P. Bridle, S.J. Bellworthy, C. Garcia-Viguera, H.P. Reader, and S.J. Watkins. 1998. Effect of sulphur dioxide and must extraction on colour, phenolic composition and sensory quality of red table wine. J. Sci. Food Agric. 78:297-307.

Blanco-Vega, D., F.J. López-Bellido, J.M. Alía-Robledo, and I. Hermosín-Gutiérrez. 2011. HPLC-DAD-ESI-MS/MS characterization of pyranoanthocyanins pigments formed in model wine. J. Agric. Food Chem. 59:9523-9531.

Boulton, R. 2001. The copigmentation of anthocyanins and its role in the color of red wine: A critical review. Am. J. Enol. Vitic. 52:67-87.

Bouzanquet, Q., C. Barril, A.C. Clark, D.A. Dias, and G.R. Scollary. 2012. A novel glutathione-hydroxycinnamic acid product generated in oxidative wine conditions. J. Agric. Food Chem. 60:12186-12195.

Cano-López, M., F. Pardo-Mínguez, G. Schmauch, C. Saucier, P.L. Teissedre, J. Maria López-Roca, and E. Gómez-Plaza. 2008. Effect of micro-oxygenation on color and anthocyanin-related compounds of wines with different phenolic contents. J. Agric. Food Chem. 56:5932-5941.

Carlton, W.K., B. Gump, K. Fugelsang, and A.S. Hasson. 2007. Monitoring acetaldehyde concentrations during micro-oxygenation 
of red wine by headspace solid-phase microextraction with on-fiber derivatization. J. Agric. Food Chem. 55:5620-5625.

Cejudo-Bastante, M.J., I. Hermosín-Gutíerrez, and M.S. Pérez-Coello. 2011a. Micro-oxygenation and oak chip treatments of red wines: Effects on colour-related phenolics, volatile composition and sensory characteristics. Part I: Petit Verdot wines. Food Chem. 124:727-737.

Cejudo-Bastante, M.J., M.S. Pérez-Coello, and I. Hermosín-Gutíerrez. 2011b. Effect of wine microoxygenation treatment and storage period on colour-related phenolics, volatile composition and sensory characteristics. LWT-Food Sci. Technol. 44:866-874.

Code of Federal Regulations. 2014. Materials authorized for the treatment of wine and juice, \$24.246. U.S. Government Publishing Office. http://www.gpo.gov/fdsys/pkg/CFR-1998-title27-vol1/xml/ CFR-1998-title27-vol1-sec24-246.xm1.

da Silva Ferreira, A.C., J.C. Barbe, and A. Bertrand. 2002. Heterocyclic acetals from glycerol and acetaldehyde in port wines: Evolution with aging. J. Agric. Food Chem. 50:2560-2564.

Danilewicz, J.C. 2011. Mechanism of autoxidation of polyphenols and participation of sulfite in wine: Key role of iron. Am. J. Enol. Vitic. 62:319-328.

Danilewicz, J.C., and P.J. Wallbridge. 2010. Further studies on the mechanism of interaction of polyphenols, oxygen, and sulfite in wine. Am. J. Enol. Vitic. 61:166-175.

Danilewicz, J.C., J.T. Seccombe, and J. Whelan. 2008. Mechanism of interaction of polyphenols, oxygen, and sulfur dioxide in model wine and wine. Am. J. Enol. Vitic. 59:128-136.

del Alamo-Sanza, M., V. Pando, and I. Nevares. 2014. Investigation and correction of the interference of ethanol, sugar and phenols on dissolved oxygen measurement in wine. Anal. Chim. Acta 809:162-173.

Di Stefano, R., and S. Guidoni. 1989. La determinazione dei polifenoli totali nei mosti e nei vini (Evaluation of total phenols in musts and wines). Vigne Vini 16:47-52.

Drexler, C., H. Elias, B. Fecher, and K.J. Wannowius. 1991. Kinetic investigation of sulfur (IV) oxidation by peroxo compounds R-OOH in aqueous-solution. Fresen. J. Anal. Chem. 340:605-615.

Drinkine, J., P. Lopes, J.A. Kennedy, P.L. Teissedre, and C. Saucier. 2007. Ethylidene-bridged flavan-3-ols in red wine and correlation with wine age. J. Agric. Food Chem. 55:6292-6299.

du Toit, W.J., K. Lisjal, J. Marais, and M. du Toit. 2006. The effect of micro-oxygenation on the phenolic composition, quality and aerobic wine-spoilage microorganisms of different South African red wines. S. Afr. J. Enol. Vitic. 27:57-67.

Elias, R.J., and A.L. Waterhouse. 2010. Controlling the Fenton reaction in wine. J. Agric. Food Chem. 58:1699-1707.

Elias, R.J., M.L. Andersen, L.H. Skibsted, and A.L. Waterhouse. 2009. Identification of free radical intermediates in oxidized wine using electron paramagnetic resonance spin trapping. J. Agric. Food Chem. 57:4359-4365.

Es-Safi, N.E., H. Fulcrand, V. Cheynier, and M. Moutounet. 1999. Studies on the acetaldehyde-induced condensation of (-)-epicatechin and malvidin 3-O-glucoside in a model solution system. J. Agric. Food Chem. 47:2096-2102.

Fell, A.J., S.I. Dykes, L. Nicolau, and P.A. Kilmartin. 2007. Electrochemical microoxidation of red wine. Am. J. Enol. Vitic. 58:443-450.

Finley, J.W., E.L. Wheeler, and S.C. Witt. 1981. Oxidation of glutathione by hydrogen peroxide and other oxidizing agents. J. Agric. Food Chem. 29:404-407.

Fulcrand, H., P. J. Cameira dos Santos, P. Sarni-Manchado, V. Cheynier, and J. Favre-Bonvin. 1996. Structure of new anthocyanin-derived wine pigments. J. Chem. Soc., Perkin Trans. 1 7:735-739.

Fulcrand, H., V. Atanasova, E. Salas, and V. Cheynier. 2004. The fate of anthocyanins in wine: Are there determining factors? In Red Wine
Color: Revealing the Mysteries. A.L. Waterhouse and J.A. Kennedy (eds.), pp. 68-88. American Chemical Society, Washington, DC.

Gambuti, A., A. Rinaldi, M. Ugliano, and L. Moio. 2013. Evolution of phenolic compounds and astringency during aging of red wine: Effect of oxygen exposure before and after bottling. J. Agric. Food Chem. 61:1618-1627.

Glories, Y. 1984. La couleur des vins rouges. $1^{\circ}$ et $2^{\circ}$ partie. Conn. Vigne Vin 18:253-271.

Gómez-Plaza, E., and M. Cano-López. 2011. A review on microoxygenation of red wines: Claims, benefits and the underlying chemistry. Food Chem. 125:1131-1140.

Hagerman, A.E., Y. Zhao, and S. Johnson. 1997. Methods for determination of condensed and hydrolyzable tannins. In Antinutrients and Phytochemicals in Food. F. Shahidi (ed.), pp. 209-222. American Chemical Society, Washington, DC.

Han, G., H. Wang, M.R. Webb, and A.L. Waterhouse. 2015. A rapid, one step preparation for measuring selected free plus $\mathrm{SO}_{2}$-bound wine carbonyls by HPLC-DAD/MS. Talanta 134:596-602.

Harbertson, J.F., E.A. Picciotto, and D.O. Adams. 2003. Measurement of polymeric pigments in grape berry extracts and wines using a protein precipitation assay combined with bisulfite bleaching. Am. J. Enol. Vitic. 54:301-306.

He, F., N.N. Liang, L. Mu, Q.H. Pan, J. Wang, M.J. Reeves, and C.Q. Duan. 2012. Anthocyanins and their variation in red wines I. Monomeric anthocyanins and their color expression. Molecules 17:1571-1601.

Iland, P., N. Bruer, G. Edwards, S. Caloghiris, and E. Wilkes. 2004. Analysis methods. In Chemical Analysis of Grape and Wine: Techniques and Concepts. Patrick Iland Wine Promotions Pty Ltd, Campbelltown, Australia.

Jackman, R.L., R.Y. Yada, M.A. Tung, and R.A. Speers. 1987. Anthocyanins as food colorants-A review. J. Food Biochem. 11:201-247.

Kritzinger, E.C., F.F. Bauer, and W.J. du Toit. 2013. Role of glutathione in winemaking: A review. J. Agric. Food Chem. 61:269-277.

Laurie, V.F., R. Law, W.S. Joslin, and A.L. Waterhouse. 2008. In situ measurements of dissolved oxygen during low-level oxygenation in red wines. Am. J. Enol. Vitic. 59:215-219.

Martins, R.C., A.R. Monforte, and A.S. Ferreira. 2013. Port wine oxidation management: A multiparametric kinetic approach. J. Agric. Food Chem. 61:5371-5379.

McCord, J. 2003. Application of toasted oak and micro-oxygenation to aging of Cabernet Sauvignon wines. Aust. NZ Grape Wine. 474:43-53.

Mouls, L., and H. Fulcrand. 2012. UPLC-ESI-MS study of the oxidation markers released from tannin depolymerization: Toward a better characterization of the tannin evolution over food and beverage processing. J. Mass Spectrom. 47:1450-1457.

Nevares, I., M. del Alamo, and C. Gonzalez-Muñoz. 2010. Dissolved oxygen distribution during micro-oxygenation. Determination of representative measurement points in hydroalcoholic solution and wines. Anal. Chim. Acta 660:232-239.

Nikolantonaki, M., and A.L. Waterhouse. 2012. A method to quantify quinone reaction rates with wine relevant nucleophiles: A key to the understanding of oxidative loss of varietal thiols. J. Agric. Food Chem. 60:8484-8491.

Peng, Z., P.G. Iland, A. Oberholster, M.A. Sefton, and E.J. Waters. 2002. Analysis of pigmented polymers in red wine by reverse phase HPLC. Aust. J. Grape Wine Res. 8:70-75.

Peterson, A.L., A. Gambuti, and A.L. Waterhouse. 2015. Rapid analysis of heterocyclic acetals in wine by stable isotope dilution gas chromatography-mass spectrometry. Tetrahedron 71:3032-3038.

Saucier, C.T., and A.L. Waterhouse. 1999. Synergetic activity of catechin and other antioxidants. J. Agric. Food Chem. 47:4491-4494. 
Schmidtke, L.M., A.C. Clark, and G.R. Scollary. 2011. Micro-oxygenation of red wine: Techniques, applications, and outcomes. Crit. Rev. Food Sci. Nutr. 51:115-131.

Sonni, F., A.C. Clark, P.D. Prenzler, C. Riponi, and G.R. Scollary. 2011a. Antioxidant action of glutathione and the ascorbic acid/glutathione pair in a model white wine. J. Agric. Food Chem. 59:3940-3949.

Sonni, F., E.G. Moore, A.C. Clark, F. Chinnici, C. Riponi, and G.R. Scollary. 2011b. Impact of glutathione on the formation of methylmethine- and carboxymethine-bridged $(+)$-catechin dimers in a model wine system. J. Agric. Food Chem. 59:7410-7418.

Tao, J., S.I. Dykes, and P.A. Kilmartin. 2007. Effect of $\mathrm{SO}_{2}$ concentration on polyphenol development during red wine micro-oxygenation. J. Agric. Food Chem. 55:6104-6109.
Vernhet, A., S. Carrillo, and C. Poncet-Legrand. 2014. Condensed tannin changes induced by autoxidation: Effect of the initial degree of polymerization and concentration. J. Agric. Food Chem. 62: 7833-7842.

Waterhouse, A.L., S.F. Price, and J.D. McCord. 1999. Reversed-phase high-performance liquid chromatography methods for analysis of wine polyphenols. Method Enzymol. 299:113-121.

Winterbourn, C.C., and D. Metodiewa. 1999. Reactivity of biologically important thiol compounds with superoxide and hydrogen peroxide. Free Radic. Biol. Med. 27:322-328. 